\title{
SPIRITUAL LEADERSHIP AND ORGANIZATIONAL CITIZENSHIP BEHAVIOR: EXPLORING THE CONDITIONAL EFFECTS OF SELF-DETERMINATION AND CONFUCIAN MINDSET
}

\author{
William D. Hunsaker* \\ Kyungpook National University
}

\begin{abstract}
Today's workers are increasingly expected to work autonomously while also working beyond assigned responsibilities as organizational citizens. Effective leadership facilitates this process. This paper proposed that the intrinsic motivational aspects of self-determination mediate the relationship between spiritual leadership and organizational citizenship behavior (OCB). Moreover, given that the effectiveness of leadership theory requires a congruency with cultural values when testing in non-western cultures, this paper proposed that Confucian values moderate the relationship between one's perceived self-determination and OCBs in Confucian-centric cultures. Results confirmed that self-determination mediated the proposed relationship. Additionally, the results confirmed that Confucian values moderate the relationship between self-determination and citizenship behavior to the organization (OCBO). The results of this study increase our understanding of how and under what conditions spiritual leadership influences employee participation in citizenship behaviors.
\end{abstract}

Keywords: Confucian Values; Meaning; Organizational Citizenship Behavior; Psychological Empowerment; SelfDetermination; Spiritual Leadership; Workplace Spirituality.

\section{INTRODUCTION}

Today's workers face complex, conflicting challenges. They are confronted with not only unprecedented levels of uncertainty and constant change, but also with the expectation to take on extra work roles and responsibilities for the betterment of the organization, a behavior known as organizational citizenship behavior (Organ, 1988). Organizational citizenship behaviors (OCB) are supported by diverse leader behaviors with supportive leadership behavior and leader modeling of expected assumptions and traditions functioning as key mechanisms in enabling the relationship to OCBs (Bandura, 1986; Podsakoff et al., 2000; Schein, 2004). Workers are also faced with greater organizational decentralization and the push for horizontal structures and collaborative decision-making that is pressuring them to work more autonomously and regulate personal actions about one's work, a motivational need recognized as self-determination (Deci \& Ryan, 1985; Pfeffer, 2010). This paper posits that to help employees cope with these diverse challenges and more fully embrace OCBs, organizations must rely on effective leadership, buttressed by a supportive, empowering organizational culture, which can be found in spiritual leadership.

Spiritual leadership (Fry, 2003) posits an interactive relationship between leaders and followers, underpinned by a supportive, altruistic organizational culture, which empowers workers through a sense of work meaning and intrinsically motivates employees to work for the betterment of the organization

\footnotetext{
* Corresponding Author: William D. Hunsaker, Assistant Professor, Kyungpook National University, 80 Daehak-ro, Buk-gu, Daegu, South Korea. Phone: +82539507418. Email: hunsaker@knu.ac.kr
} 
(Fry \& Nisiewicz, 2013). Spiritual leadership research has shown that workers' OCBs, such as organizational loyalty, helping solve coworkers' problems, or assuming responsibility for the well-being of coworkers, are impacted by supportive leadership behaviors that enable employees' sense of work meaning, or empowerment (Chen \& Yang, 2012; Hunsaker, 2016). Empowerment is comprised of four core dimensions, including not only a sense of meaning as integrated in Fry's spiritual leadership model but also competence, impact, and a sense of self-determination (Spreitzer, 1995). Self-determination can motivate workers to not only extend one's capacities, but also regulate their behavior to assume new responsibilities and participate in activities that are not interesting (Deci \& Ryan, 1985; Ryan \& Deci, 2000). However, the impact of self-determination on workers' OCBs has not been researched sufficiently, which poses a significant research gap, given the increasing expectations facing today's employees to not only work more autonomously but also to take on discretionary work roles and responsibilities.

The cultural context of this study is Confucianism in South Korea, in support of the view that the emic manifestations of a leadership theory should be considered when attempting to generalize a western leadership theory to outside cultures (House \& Aditya, 1997), wherein the effectiveness of the theory requires congruency with one's cultural values (Robert et al., 2000). The advent of modernity and "westernization" of East Asia from the late 19th century upended traditional Confucian traditions, replaced by capitalism and the Protestant work ethic, which led many intellectuals to claim Confucianism was a dead tradition (Bell \& Hahm, 2003). However, according to Bell and Hahm, practitioner interest in Confucian philosophies has seen renewed interest, based on the humanistic and moral elements found within the Confucian tradition and in response to the perceived underlying moral and ethical decay in many of today's organizations. As an eclectic mix of Confucian and western traditions, the culture of South Korea represents this conflict between tradition and modernity. Despite westernization, the cultural identity of Korea and its organizations today remain highly connected to Confucian philosophies (Hemmert, 2012; Hofstede \& Hofstede, 2005). Underpinning these philosophies within organizations are deeply embedded Confucian values that espouse not only humanity, loyalty, and courtesy to help coworkers or promote the company image (i.e., OCB), but also self-cultivation through constant learning and regulating one's actions for the benefit of both self and the group at large (i.e., self-determination; Schuman, 2015; Woods \& Lamond, 2011). Therefore, this paper proposes that Confucian cultural values moderate the relationship between self-determination and OCB, by exploring for what levels of Confucian values self-determination exerts the most effect on OCB.

This paper builds on research by Hunsaker (2016) that focused on the relationship between spiritual leadership and OCB and explored the mediating effects of spiritual well-being on this relationship. In contrast, the primary focus and purpose of this paper is to examine how the empowerment dimension of self-determination functions as a mediating mechanism in the relationship between spiritual leadership and OCBS, as a means of better understanding how the influence of spiritual leadership on OCBs can help organizations and employees deal with uncertainty and change. Additionally, given the Confucian cultural context of this paper, this research also explores how the level of employees' OCB in a Confucian context is explained by the degree to which employees endorse Confucian values; hence, an exploration of how Confucian mindset moderates the relationship between self-determination and OCBs.

\section{LITERATURE REVIEW}

\subsection{Spiritual leadership and organizational citizenship behavior}

Organizational citizenship behavior (OCB) has traditionally been characterized as discretionary behavior beyond assigned roles and responsibilities (Organ, 1988), including such facets as cooperating 
with others, protecting and maintaining a favorable attitude toward the organization, and volunteering constructive ideas (Katz, 1964; Podsakoff et al., 2000). Over time and based on emerging empirical evidence, this perspective has evolved beyond an "extra-role" characterization to "performance that supports the social and psychological environment in which task performance takes place (Organ, 1997, p. 95). Hence, Bolino and Turnley (2003) posit that OCB creates social capital among employees "from the willingness of employees to exceed their formal job requirements in order to help each other, to subordinate their individual interests, ... and to take a genuine interest in the organization's activities" (p. 61). Moreover, at its core, OCB is focused on supporting organizational effectiveness through contextual employee performance; in other words, the behavior contributes to the context of the role, job, or task for the betterment of the organization (Organ, 1997; Podsakoff et al., 2009). OCBs can be classified into two broad categories, according to whether the behavior is directed towards and primarily benefits the organization (OCBO) or is indirectly beneficial to the organization through the effect on specific individuals (OCBI) in the organization (Williams and Anderson, 1991). As antecedents, research suggests that individual and organizational characteristics related to roles, attitudes, and behaviors contribute positively to OCBs (Organ et al., 2006). One such contributing factor is leadership, of which there is considerable research showing that values-based leadership has a positive relationship with OCB (Podsakoff et al., 2000).

Spiritual leadership (Fry, 2003) is an emerging theory of values-based leadership with links to Covey's (1991) theory of principle-centered leadership, Greenleaf's (1977) theory of servant leadership, and Bass and Avolio's (1994) theory of transformational leadership. Spiritual leadership finds its roots in the field of workplace spirituality, a construct that is characterized by meaningful and interesting work, a sense of connection and positive social relations, and the ability to live an integrated life of aligned individual and organizational values (Fry, 2003; Giacolone \& Jurkiewicz, 2003; Milliman et al., 2003; Pfeffer, 2010). Spiritual leadership assumes that organizations and leaders embrace the principles and values of a learning organization, such as being flexible, empowering, and collaborative, which allow employees to be open, interested in, and connected with others, pursue the growth of both self and others, and take risks (Garavan, 1997; Senge, 1990). Spiritual leadership is based on a model of intrinsic motivation, wherein effort leads to performance leads to intrinsic rewards, which in turn loop back to effort while at the same time also re-influencing performance, with the three dimensions operationalized in spiritual leadership as faith/hope, vision, and altruistic love, respectively (Fry, 2003). Based on these underpinnings, Fry (2003) defines spiritual leadership as "the values, attitudes, and behaviors that are necessary to intrinsically motivate one's self and others so that they have a sense of spiritual survival [well-being]" (p. 711).

Spiritual leadership research has determined a predictive relationship between the combined interactive effects of the three dimensions of spiritual leadership and diverse organizational attitudes, such as organizational commitment, productivity, and OCB (Fry \& Nisiewicz, 2013; Hill et al., 2013; Hunsaker, 2016; Jeon et al., 2013). The primary mechanism enabling the influence of spiritual leadership is employees' sense of spiritual well-being, operationalized as a sense of meaning and membership in the organization (Fry, 2003). Spillover theory (Diener, 1984; Wilensky, 1960) explains the relationship between spiritual leadership and employees' sense of spiritual well-being. Based on this premise, spiritual well-being is enabled through the positive spillover effects of the social exchange between leaders and employees (Cropanzano \& Mitchell, 2005; Edwards \& Rothbard, 2000). For example, according to Fry, the vision and culture of an organization, enacted through social exchange, play a critical role in rousing employees' sense of well-being. Particularly, vision, if mutually shared and inspiring, helps employees feel like they are making a difference, while an organizational culture rooted in values of altruistic love like respect, honesty, and compassion, helps employees feel appreciated and part of the organizational community. Hence, the effects of spiritual leadership spill over to employees' 
spiritual well-being, arousing a sense of meaning and membership, which in turn enable the realization of positive organizational outcomes.

Research has begun to identify a positive relationship between workplace spirituality and OCBs. Kazemipour et al. (2012) determined that workplace spirituality positively influences OCB, as workplace spirituality aligns personal goals with organizational values, which sparks a connection of employees to their jobs and coworkers. Through the lens of spiritual leadership, Chen and Yang (2012) determined that spiritual leadership impacts workers' OCBs by promoting altruistic values and emphasizing supportive and visionary leader behaviors, as evidenced by employees helping solve coworkers' problems, practicing organizational loyalty, and taking initiative to go the extra mile. Likewise, Hunsaker (2016) found spiritual leadership positively influenced employee OCBs through the mediating effects of employees' spiritual well-being, which helped sustain organizational harmony through the willingness of employees to volunteer personal time and knowledge. These views are supported by extensive research (Podsakoff et al., 2000) on the relationship between OCB and leadership theories (e.g., transformational leadership, path-goal theory of leadership, leader-member exchange theory of leadership), which has consistently shown that leader behavior influences employees' OCB through the reciprocal social exchange between leaders and followers, supportive leader behavior, and leader modeling of expected assumptions and traditions (Bandura, 1986; Cropanzano \& Mitchell, 2005; Schein, 2004).

\subsection{Mediating role of self-determination}

Along with a sense of meaning in one's work, self-determination is another core cognitive dimension of psychological empowerment (Spreitzer 1995), defined as "a sense of choice in initiating and regulating one's own actions" (Deci et al., 1989, p. 580). According to Ryan and Deci (2017), selfdetermination is driven by innate individual needs to seek control of outcomes (e.g., competence), to connect with others (e.g., relatedness), and to be a causal agent of one's own life (e.g., autonomy) and is rooted in human motivation. Within the field of organizational behavior, self-determination is researched as a core component of psychological empowerment (Spreitzer, 2008). This view of empowerment is rooted in the motivational aspects of expectancy (Lawler, 1973) and self-efficacy theories (Bandura, 1986), which emphasizes the psychological states of individuals, enhanced through organizational practices that create a sense of self-efficacy and personal control about one's work (Conger and Kanungo, 1988). The primary objective of such empowerment is to actively enable a person's psychological states as pertains to one's work role by focusing on the cognitive states of meaning, competence, impact, and self-determination (Spreitzer, 1995). These four states relate to one's perceived work value, feeling of self-efficacy, ability to influence, and job autonomy, respectively.

The antecedents of self-determination, as captured by self-determination theory (Deci \& Ryan, 1985) and also encapsulated in empowerment research, can be viewed from several contextual dimensions, including socio-political support, high-performance managerial practices, and leadership (Seibert et al., 2011). Socio-political support suggests that employees' sense of self-determination will be stimulated through feelings of organizational support in determining individual work goals and strategies (Spreitzer, 1995). High-performance managerial practices stimulate employees' sense of self-determination by allowing employees to determine what actions to initiate and regulate within the broader organizational context (Zhang \& Chen, 2013). Finally, leadership shapes the work experience of followers through the sharing of strategic goals and visions, which addresses employees' intrinsic motivations for greater participation and autonomy (Gagné \& Deci, 2005). Spiritual leadership posits similar tenets, based on underlying values such as trust, compassion, and empathy that create a sense of organizational support by understanding and accepting employees (Fry, 2003). Spiritual leadership also specifically assumes 
the open communication of a compelling vision to create a sense of employee purpose that will spark initiative and excellence from employees. Furthermore, the spiritual leadership process is underpinned by intrinsic motivation that respects, values, and rewards employee contributions and participation through a sense of altruism (Fry \& Nisiewicz, 2013). Therefore, this paper expects spiritual leadership to be positively related to employees' sense of self-determination.

Research has shown that self-determination impacts OCB. Zhong et al. (2011) determined that one's sense of self-determination allows an individual to more freely regulate when and how to participate in OCBs. Wat and Shaffer (2005) found a significant relationship between self-determination and citizenship behaviors related to altruism and conscientiousness. A sense of fairness and quality interpersonal relationships between leaders and employees supported employees' engagement in OCBs with results suggesting that helping others may actually enhance one's feelings of autonomy. According to self-determination theory, feelings of autonomy are linked to both extrinsic and intrinsic motivation that describe the inherent drive to not only seek out challenges and extend one's capacities, but also regulate one's behavior to assume new responsibilities and participate in activities that are not interesting (Ryan \& Deci, 2000). OCB is defined as discretionary and outside of assigned roles (Organ, 1988), suggesting that one who endorses OCB is making an intentional choice to assume new responsibilities that are likely deemed uninteresting, challenging, and/or unrewarding. This paper argues that despite the potential uninteresting, challenging, or unrewarding aspects that may be characteristic of OCB, selfdetermined employees will endorse OCBs, thanks to a sense of free choice, connection with others, and drive to extend one's capacities (Ryan \& Deci, 2017) that comes from intrinsic motivational rewards and supportive leadership behaviors central to spiritual leadership (Fry, 2003). This argument is consistent with past research, showing that self-determination functions as a mediating mechanism on OCB, helped by the role that leaders play in influencing employees' feelings of self-determination (Zhang \& Chen, 2013).

In summary, spiritual leadership impacts organizational citizenship behavior (Chen \& Yang, 2012). The question is how spiritual leadership might exert its effect on citizenship behaviors. Research to date has shown spiritual well-being is one mechanism impacting this relationship through both an employees' sense of membership and sense of meaning, a key dimension of psychological empowerment (Chen \& Yang, 2012; Hunsaker, 2016). This paper argues that employees' sense of self-determination will also impact spiritual leadership's effect on OCBs, underpinned by the altruistic values and supportive leadership practices of spiritual leadership that provide employees a free choice to extend one's capacities beyond assigned responsibilities.

Hypothesis 1: Self-determination will mediate the relationship between spiritual leadership and OCBO and OCBI.

\subsection{Moderating role of Confucian values}

In response to the question of how spiritual leadership exerts its effect on OCB, this paper has proposed that self-determination can play a critical role. However, within a Confucian cultural context, a key question is for what levels of Confucian values does self-determination exert the most effect on OCB. Self-determination (and other dimensions of empowerment) does not always induce an individual to endorse citizenship behaviors. Rather research suggests that individuals exhibit self-determination based on perceived underlying motivational values, which are a function of one's internalization and integration of the perceived values (Ryan \& Deci, 2000) and social cognitive learning (Bandura, 1986). According to Bandura, individuals learn and internalize social values through observing others, influenced by one's perceptions as relates to individual cognition, behavior, and the associated 
environment. Thus, a key determinant of the effect of self-determination on an individual is embedded in how self-determination is perceived.

This paper proposes that a key component of how self-determination is individually interpreted, and whether an individual embraces OCB, depend on the cultural values internalized through one's social cognitive interactions. Extensive research highlight the importance of cultural values in shaping individual attitudes and behavior across diverse cultures, led by Hofstede's (2001) seminal identification of cultural differences related to dimensions such as power distance and individualism, and more recently through the GLOBE studies on leadership differences across cultures (House et al., 2004). Of importance to this study are the cultural values embedded in these cultural dimensions, as relates to Confucianism (Ryu, 2007), or a Confucian mindset (Hunsaker, 2014; 2016). Thus, this paper examined how a Confucian mindset influences employee identity, thereby influencing one's perceived selfdetermination. The proposed interaction between a Confucian mindset and self-determination suggests that a Confucian mindset can cause employees to more actively enact OCBs. That is a Confucian mindset can moderate the relationship between self-determination and OCBs.

A Confucian mindset is underpinned by the Confucian Golden Rule (Analects 6:30) and the Golden Mean (Doctrine of the Mean 1:4) that explain the values and behaviors that a virtuous person should exhibit in interpersonal relationships. For example, an individual should not do to others what they do not want done to themselves, and a person of virtue should behave with tolerance, propriety, and mutual reciprocity. Confucian values and behaviors are guided by the five Confucian constants, commonly known as ren, $l i, y i$, zhi, and $x i n$, which explicitly detail the various values, attitudes, and rules of appropriate social behavior required to maintain harmony, develop oneself and others, and live virtuously (Kim \& Shute, 1993). How these values are reflected individually within organizational contexts can influence the effect on organizational outcomes. For example, ren suggests amongst its principles, a sense of responsibility to work beyond assigned duties through personal initiative, subordination of personal interests, and conscientiousness (Daly et al., 2015). Moreover, these Confucian practices enhance loyalty and respect between employees by showing how employees should reciprocally behave towards each other, based on age, rank, or status, in pursuing group harmony (Hemmert, 2014, Kim \& Park, 2003).

A Confucian mindset is evident in organizational citizenship behavioral dimensions. Confucian attitudes towards harmony and group orientation imply that employees are expected to contribute to the betterment of the organization outside of assigned roles (Han \& Altman, 2010). Hunsaker (2016) found that a Confucian mindset, comprised of values such as empathy, conscientiousness, respect, and conviction, strongly influenced the relationship between spiritual leadership and both OCBO and OCBI. This study was based on Confucian values innately tied to the culture of Korea (Ryu, 2007) that have been reliably confirmed to influence subordinate trust in leadership (Ryu \& Lee, 2010). Outside of Korea, Farh et al. (2004) found that the formation of OCBs in China was influenced by embedded cultural contexts, including Confucianism, which were generally aligned with Western reflections of OCB dimensions. Becton and Field (2009) also determined that collectivism motivated employees to engage in citizenship behaviors supportive of the organization.

Self-determination, as a dimension of empowerment, can appear to be at odds with a Confucian mindset, due to the emphasis on social order and harmony that can often dominate organizational life through strict hierarchical, vertical relationships, restrained self-interests, and an emphasis on duty (Kirkman \& Shapiro, 2001). However, the underlying core of the five virtues of Confucianism emphasizes not only harmonious relationships, but also personal responsibility for one's actions, self-cultivation, and contribution to the greater whole in the pursuit of becoming a person of virtue (Woods \& Lamond, 2011). 
Confucian-led cultures are renowned for the emphasis on education/training, or self-cultivation, which can be considered a form of self-empowerment, in which the individual is seeking to take charge of one's life, through the cultivation of skills and knowledge that can benefit both the individual and the group at large (Hemmert, 2014; Schuman, 2015). Hence, cultural values may be a moderator in how employees experience empowerment, or self-determination, and the influence on OCB. For example, Fock et al. (2011) found that collectivism moderates the relationship between empowerment dimensions and job satisfaction. Notably, a strong collectivist orientation strengthened the effect of selfdetermination on job satisfaction. Farh et al. (2007) observed cultural values in China as a moderating variable on the relationship between perceived organizational support and diverse work outcomes, including aspects of OCB. Cultural values included traditionality, or the extent to which an individual endorses the traditional hierarchal role relationship emphasized in Confucian practices. Their research found that traditionality had significant, moderating effects on the OCB dimensions of altruism and conscientiousness. Accordingly, this study contends a Confucian mindset will moderate the relationship between self-determination and OCBs, wherein the relationship between self-determination and OCBs will be stronger among employees who endorse Confucian mindset and vice versa.

Hypothesis 2: Confucian mindset will moderate the relationship between self-determination and OCBO and OCBI.

Figure 1: Proposed model of mediation and moderation effects

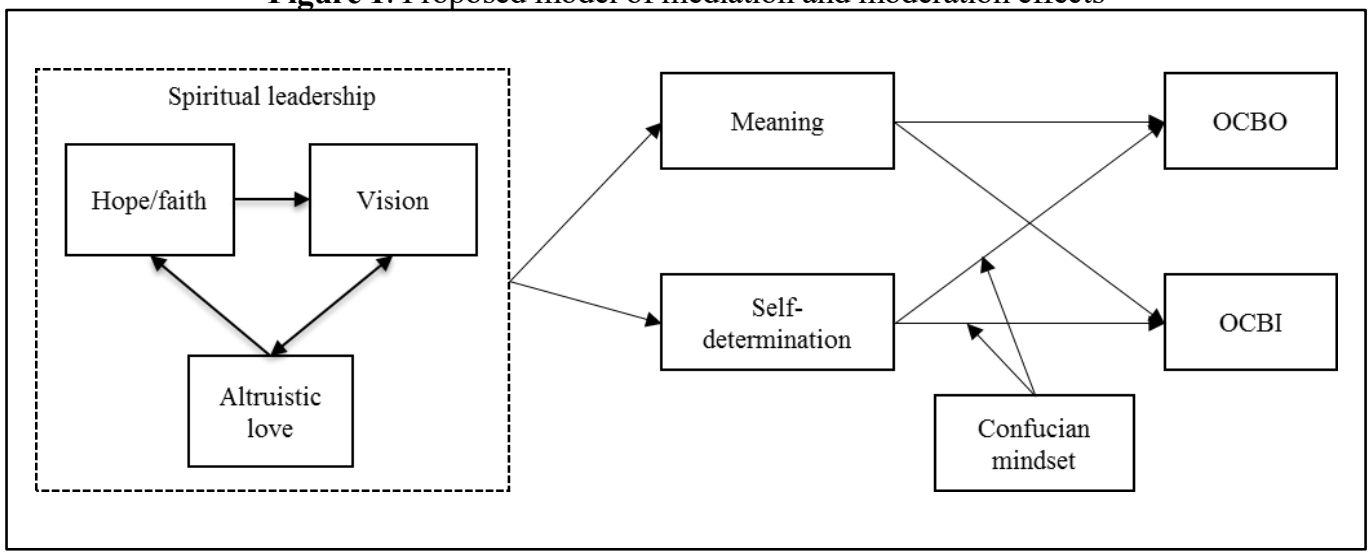

\section{METHOD}

\subsection{Sample and data collection}

Participants in this study were employees of two emerging biotech companies in Korea, pioneering their respective fields. Based on the underlying assumption of spiritual leadership that organizational culture is keenly influenced by the attitudes, values, and behaviors of company founders, this industry was deemed an attractive population that would reflect the influence of company founders, given that most organizations in the industry were relatively young with company founders generally still holding executive positions within the organizations. Hence, the two firms in this study were purposively chosen as representative samples, exemplified by the company founders holding executive leadership positions and the organizational cultures deemed to be representative of both Confucian and spiritual leadership values. 
Questionnaires were distributed to approximately 500 employees of the two firms, including staff and managers at all levels of the companies, of which 263 surveys were returned and 256 completed questionnaires deemed usable. In the sample of participants, $67 \%$ were males, $20 \%$ were under the age of $30,79 \%$ were between ages 30 and $49,59 \%$ held college degrees, and $31 \%$ had earned post-graduate degrees. $62 \%$ of employees had worked for at least three years, $58 \%$ of participants had worked in the same department at least three years, and $18 \%$ of participants were classified as managers. Finally, the majority of employees worked in departments that generally assume a degree of empowerment, or selfdetermination, in order to effectively achieve job requirements, including R\&D ( $26 \%$ of participants) and sales ( $24 \%$ of participants).

\subsection{Instrumentation}

Instrumentation for spiritual leadership was based on 13 survey items from the extended spiritual leadership survey (Fry, 2008) for the three dimensions of hope/faith, vision, and altruistic love. The spiritual leadership survey is based on 5-point Likert scales, ranging from strongly disagree to strongly agree. "My organization's vision inspires my best performance" and "My organization is trustworthy and loyal to its employees" are sample items from these scales.

Instrumentation for OCB was adapted from Lee and Allen's (2002) survey of citizenship behaviors. The scale consisted of two dimensions and eight items that measure OCB to the individual (OCBI) and four items that measure OCB to the organization (OCBO), and was based on 7-point Likert scales, ranging from strongly disagree to strongly agree. "I demonstrate concern about the image of the organization" and "I assist others with their duties" are sample items from these scales.

Instrumentation for self-determination and meaning was adapted from Spreitzer's (1995) measure of empowerment. The scale consisted of three items each for the two dimensions, based on 5-point Likert scales, ranging from strongly disagree to strongly agree. "I can decide on my own how to go about doing my work" and "The work I do is meaningful to me" are sample items from these scales.

Instrumentation for Confucian mindset was based on six values selected from Ryu's (2007) Korean Confucian Values Survey (KCVS), which asks participants to self-rate the importance of each Confucian value, based on 7-point Likert scales, ranging from no importance to supreme importance. Research has shown these six items reliably load on two first-order factors, named relational harmony and Confucian work ethic, and a higher second-order latent factor, called Confucian mindset (Hunsaker, 2016).

\section{RESULTS}

\subsection{Confirmatory factor analysis}

Confirmatory factor analysis (CFA) was used to test the validity of this study. Various measures were used to assess the goodness-of-fit (GOF) of the hypothesized structural model, including the comparative fit index (CFI), non-normed fit index (NNFI), and root-mean square error of approximation (RMSEA; Bentler \& Bonett, 1980; Browne \& Cudeck, 1993; Tucker \& Lewis, 1973). The hypothesized nine-factor model (i.e., first-order model) revealed adequate fit across all measures $\left(X^{2}=914.05, \mathrm{df}=\right.$ $593, \mathrm{CFI}=.94, \mathrm{NNFI}=.93, \mathrm{RMSEA}=.05)$. Based on these positive results, a next step was to explore the existence of higher-order, latent factors. According to Marsh and Hocevar (1985), the use of a second-order factor is justified if the comparative coefficient between the chi-square ratio of the first 
order and second order models approaches a coefficient of 1.00. Hence, the GOF of a second-order structural model was examined for the three dimensions of spiritual leadership and the two dimensions of Confucian mindset with results showing slightly lower but adequate threshold fit $\left(X^{2}=923.37, \mathrm{df}=\right.$ $574, \mathrm{CFI}=.93, \mathrm{NNFI}=.93, \mathrm{RMSEA}=.05)$. Notably, the comparative chi-square ratio coefficient of the first-order model $\left(X^{2}=914.05\right)$ to the second-order model $\left(X^{2}=923.37\right)$ approached a coefficient of 1.00. Therefore, the second order structural model was used in hypothesis testing (see Figure 2).

Convergent and discriminant validity of the scales were also tested by examining the variance extracted (AVE) and composite reliabilities (CR) of the scales (Fornell \& Larcker, 1981). As shown in Table 1, the AVE of all scales was adequate $(>.50)$ while the CR of all measures was above .75 , evidence of the convergent validity of the measures. Moreover, all measures demonstrated discriminant validity, as evidenced by the square of the parameter estimate between two variables being less than the average extracted estimates of the two factors (Anderson \& Gerbing, 1988).

\subsection{Descriptive statistics}

Table 1 shows the descriptive statistics of this study, including means, standard deviations, correlations, and reliability coefficients. All measures were correlated with each other, ranging from .18 to .69, were consistent with the hypotheses. Notably, the correlations between spiritual leadership variables (i.e., hope/faith, vision, and altruistic love) were high, ranging between .57 and .69, supportive of the latent, second-order factor of spiritual leadership determined through CFA. All measures displayed an acceptable level of internal consistency with reliabilities ranging between .81 and .90 .

Table 1: Reliability and validity analysis of variables $(N=256)$

\begin{tabular}{lcccccccccccc}
\hline \hline & Variable & M & SD & AVE & $\mathbf{1}$ & $\mathbf{2}$ & $\mathbf{3}$ & $\mathbf{4}$ & $\mathbf{5}$ & $\mathbf{6}$ & $\mathbf{7}$ & $\mathbf{8}$ \\
\hline 1 & Hope/faith & 3.69 & .65 & .58 & $\mathbf{. 8 4}$ & & & & & & & \\
2 & Vision & 3.35 & .71 & .61 & .69 & $\mathbf{. 8 6}$ & & & & & \\
3 & Altruistic love & 3.22 & .83 & .64 & .57 & .69 & $\mathbf{. 8 9}$ & & & & \\
4 & Meaning & 3.87 & .73 & .74 & .59 & .56 & .42 & $\mathbf{. 9 0}$ & & & \\
5 & Self-determination & 3.41 & .83 & .67 & .21 & .30 & .38 & .30 & $\mathbf{. 8 5}$ & & \\
6 & OCBI & 5.09 & .74 & .50 & .45 & .38 & .28 & .40 & .28 & $\mathbf{. 8 9}$ & & \\
7 & OCBO & 4.58 & .89 & .52 & .55 & .47 & .47 & .47 & .44 & .56 & $\mathbf{. 8 1}$ & \\
8 & Confucian mindset & 5.66 & .75 & .61 & .42 & .38 & .29 & .41 & .18 & .51 & .43 & $\mathbf{. 8 2}$ \\
\hline \hline
\end{tabular}

Note: All correlations are significant at $\mathrm{p}<.01$. Scale reliabilities are on the diagonal in boldface.

\subsection{Hypotheses testing}

Structural equation modeling, assuming maximum likelihood estimation, was applied for testing the structural fit of hypothesized structural model. The structural fit of the model across all applied GOF measures met acceptable standards $\left(X^{2}=721.12, \mathrm{df}=421, \mathrm{CFI}=.94, \mathrm{NNFI}=.93, \mathrm{RMSEA}=.05\right)$, supporting the overall fit of this model of spiritual leadership.

Tests of mediation. Hypothesis 1 predicted an employee's sense of self-determination would mediate the relationship of spiritual leadership in OCBs. Tests of mediation were based on Baron and Kenny's (1986) and Preacher and Hayes' (2004) guidelines, examining the significance of both the direct and indirect effects of the mediator to establish mediation. The indirect effects of mediators were also tested for significance through the Sobel test, which assumes a normal distribution. However, given the possibility that the distribution is non-normal, bootstrapping with confidence intervals of the indirect 
path relationships was also conducted to probe whether the indirect effects include zero in the confidence interval, and therefore, not significant (Preacher \& Hayes, 2004).

Figure 2 shows the path results of the hypothesized relationships between spiritual leadership and OCBs, as intervened through the empowerment dimensions of self-determination and meaning. As shown, results confirmed that all path relationships were positive and significant. Next, the direct effects with mediation were calculated, which revealed that the direct effects on $\mathrm{OCBO}(\beta=.78, p<.01)$ and OCBI $(\beta=.47, p<.01)$ were significant and declined to .64 and .41 , respectively, when self-determination was added as an independent mediator. Furthermore, based on Sobel tests, spiritual leadership was found to have an indirect, mediating effect through self-determination on both $\mathrm{OCBO}(\beta=.13, p<.01)$ and OCBI $(\beta=.05, p<.05)$. Bootstrap confidence intervals at a $95 \%$ confidence interval (sample size $=5000)$ revealed confidence intervals entirely above zero with self-determination as an independent mediator to both OCBO $(.06, .22)$ and OCBI $(.00, .11)$. Finally, the interactive, mediating effects of selfdetermination and meaning were probed based on Hayes (2013) SPSS process macro, which calculates the indirect, mediating effects of multiple, parallel mediators. As shown in Table 2, the indirect effects of self-determination $(\beta=.13)$ and meaning $(\beta=.15)$ similarly mediated the relationship between spiritual leadership and OCBO, when evaluated in parallel. However, the indirect effect of meaning $(\beta$ $=.16$ ) on the relationship to OCBI was three times as large as the indirect effect of self-determination $(\beta=.05)$ on OCBI. Together, mediation analysis fully supported hypothesis 1 .

Figure 2: Simplified path analysis of proposed structural model of spiritual leadership

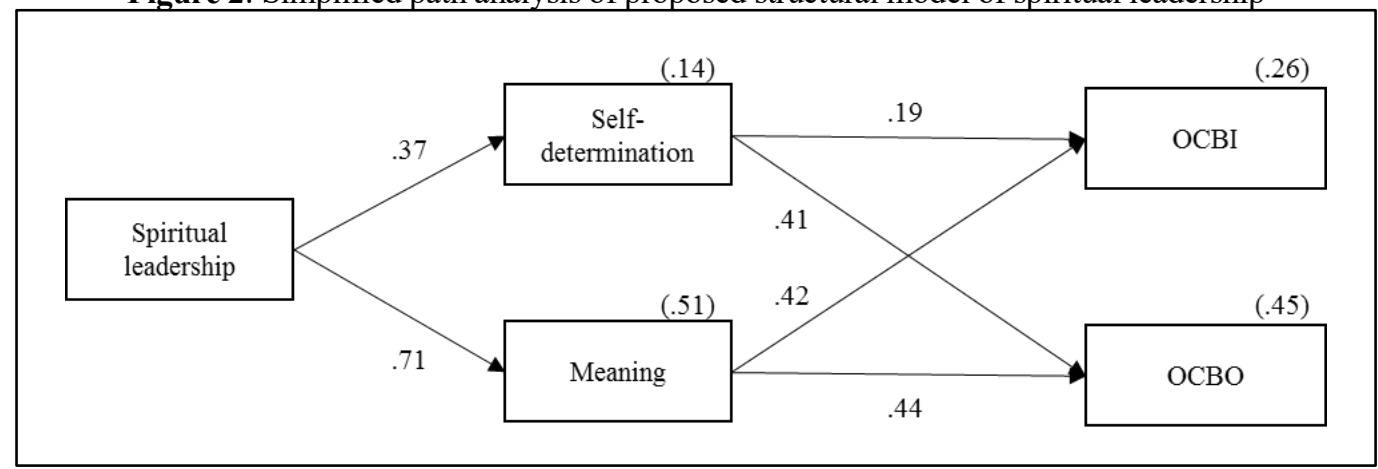

Note: Data in parentheses represent proportion of each variable's variance. All path coefficients were significant at $\mathrm{p}<.01$.

Table 2: Mediation path effects of meaning and self-determination on OCBs $(N=256)$

\begin{tabular}{ccccc}
\hline \hline \multirow{2}{*}{ Path } & \multicolumn{2}{c}{ Direct effects } & \multicolumn{2}{c}{ Indirect effects } \\
\cline { 2 - 5 } & Without mediation & With mediation & Self-determination & Meaning \\
\hline Spiritual leadership $\rightarrow$ OCBO & $.778(.000)$ & $.500(.000)$ & $.129(.000)$ & $.149(.003)$ \\
Spiritual leadership $\rightarrow$ OCBI & $.469(.000)$ & $.258(.002)$ & $.053(.052)$ & $.158(.001)$ \\
\hline \hline
\end{tabular}

Note: Data in parentheses represent $\mathrm{p}$ level of significance.

Tests of moderation. Hypothesis 2 predicted that Confucian mindset would moderate the strength of the relationship between self-determination and OCBs. Assuming these moderation hypotheses are supported, it is also reasonable to assume that the strength of the mediation effects are conditional on the values of the moderator, which Preacher et al. (2007) have termed conditional indirect effects, or moderated mediation. For example, rather than assuming the indirect effects of self-determination on the spiritual leadership to OCB relationship are independent of the potential moderating effects of Confucian mindset on this relationship, moderated mediation assumes the mediated relationship is 
contingent on different values of Confucian mindset. Accordingly, hypothesis 2 was tested to integrate the possibility of mediation effects of self-determination being contingent on the value of the proposed moderator, Confucian mindset. To test moderation, the SPSS process macro created by Hayes (2013) was utilized. The interactions were probed by the Johnson-Neyman technique (Hayes \& Matthes, 2009), which derives regions of significance that are statistically different than zero through analysis of bootstrapped confidence intervals.

Table 3: Regression results for conditional indirect effect of Confucian mindset on OCBI

\begin{tabular}{lcccc}
\hline \multicolumn{1}{c}{ Outcome variable } & Beta & SE & t & p \\
\hline $\begin{array}{l}\text { Self-determination } \\
\text { Constant }\end{array}$ & -1.60 & .26 & -6.06 & $<.01$ \\
Spiritual leadership $\rightarrow$ & .47 & .08 & 6.17 & $<.01$ \\
OCBI & & & & \\
Constant & 4.33 & .24 & 17.88 & $<.01$ \\
Self-determination $(\mathrm{SD}) \rightarrow$ & .12 & .05 & 2.40 & $<.05$ \\
Spiritual leadership $\rightarrow$ & .22 & .07 & 3.16 & $<.01$ \\
Confucian mindset $(\mathrm{CM}) \rightarrow$ & .41 & .06 & 7.12 & $<.01$ \\
SD x CM & -.02 & .06 & -.32 & .75 \\
\hline \hline
\end{tabular}

Note: $\mathrm{n}=256$. Regression coefficients are unstandardized and based on models with all variables mean centered.

Table 4: Regression results for conditional indirect effect of Confucian mindset on OCBO

\begin{tabular}{lcccc}
\hline \hline \multicolumn{1}{c}{ Outcome variable } & Beta & SE & t & p \\
\hline $\begin{array}{l}\text { Self-determination } \\
\text { Constant }\end{array}$ & -1.60 & .26 & -6.06 & $<.01$ \\
$\quad$ Spiritual leadership $\rightarrow$ & .47 & .08 & 6.17 & $<.01$ \\
OCBO & & & & \\
Constant & 2.84 & .26 & 10.79 & $<.01$ \\
Self-determination (SD) $\rightarrow$ & .28 & .05 & 5.19 & $<.01$ \\
Spiritual leadership $\rightarrow$ & .51 & .08 & 6.66 & $<.01$ \\
Confucian mindset (CM) $\rightarrow$ & .28 & .06 & 4.56 & $<.01$ \\
SD x CM & .10 & .06 & 1.68 & .09 \\
\hline
\end{tabular}

\begin{tabular}{cccccc}
\hline \multicolumn{7}{c}{ Conditional indirect effects at confidence interval percentiles } \\
\hline Percentile & Value & Effect & Boot $\boldsymbol{S E}$ & LL 95\% CI & UL 95\% CI \\
\hline 10th (very low) & -.82 & .09 & .05 & .01 & .19 \\
25th (low) & -.66 & .10 & .04 & .03 & .19 \\
50th (moderate) & .01 & .13 & .04 & .07 & .23 \\
75th (high) & .51 & .16 & .05 & .08 & .26 \\
90th (very high) & 1.18 & .19 & .07 & .07 & .33 \\
\hline \hline
\end{tabular}

Note: $\mathrm{n}=256$. Regression coefficients are unstandardized and based on models with all variables mean centered. Bootstrap sample size $=5,000 . \mathrm{LL}=$ lower limit; $\mathrm{UL}=$ upper limit; $\mathrm{CI}=$ confidence interval.

Hypotheses 2 predicted that the effects of self-determination on OCBs would be higher for individuals showing high levels of Confucian mindset and vice versa. Table 3 shows the regression path results for the conditional direct effect of Confucian mindset on OCBI and OCBO. As shown, the cross-product term between self-determination (SD) and Confucian mindset (CM) was not significant $(\beta=-.02, p$ $=.75$ ), showing Confucian mindset does not moderate the relationship between self-determination and OCBI. Figure 3 depicts the statistical diagrams of Confucian mindset as a moderator of OCBI and OCBO. In contrast, as shown in Table 4, the cross-product term between self-determination and Confucian mindset on OCBO was positive and significant $(\beta=.10, p=.09, R$-square change $=.006)$. Moreover, the slope of the relationship at one standard deviation above and below the mean of 
Confucian mindset was also examined, which showed that the slope of the relationship was positive and relatively stronger at high levels of Confucian values (simple slope $=.49, p<.01$ ) than low levels (simple slope $=.30, p<.01)$. Additionally, bootstrap confidence intervals through the Johnson-Neyman technique showed that as the effect of Confucian mindset increased from very low to very high percentiles, the $95 \%$ confidence interval was entirely above zero (see middle of Table 4 ). Notably, the moderation effect increased as the level of Confucian mindset increased from .09 at a very low level to .19 at a very high level. Hence, the data of this study partially supports the assertion of hypothesis 2 that Confucian mindset conditionally affects the level of OCBs as the level of Confucian mindset changes.

Figure 3: Statistical diagrams of Confucian mindset as a moderator of OCBI and OCBO

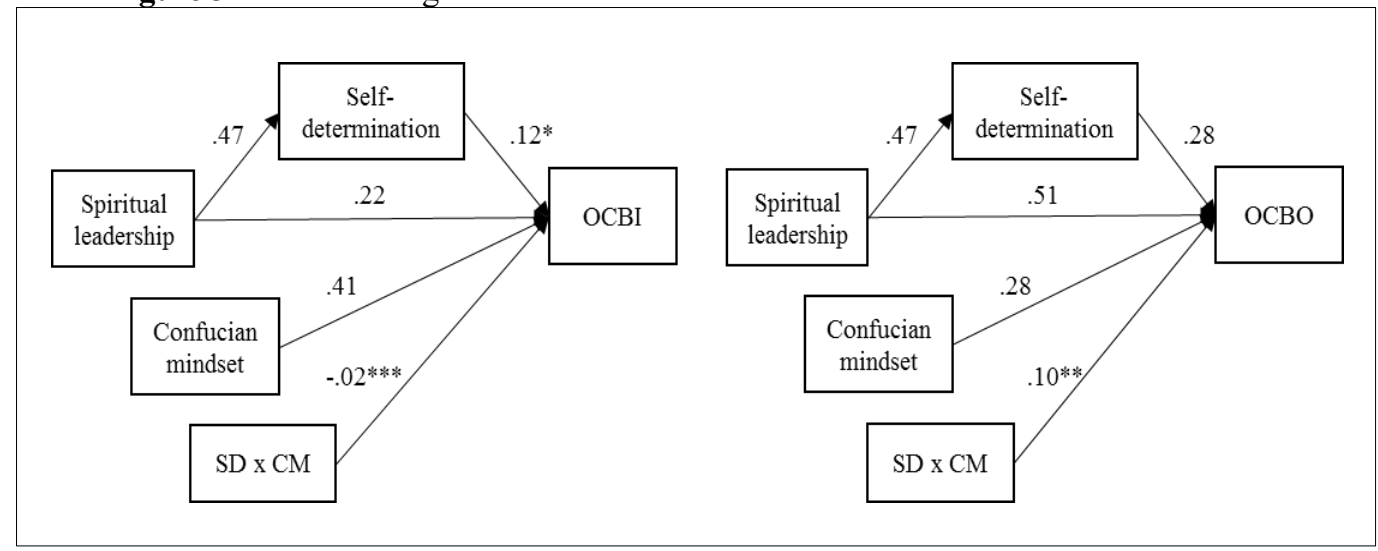

Note: $\mathrm{n}=256$. Path coefficients are unstandardized and based on models with all variables mean centered. Unless noted, $\mathrm{p}<.01$. $* \mathrm{p}<05 . * * \mathrm{p}<.10 . * * * \mathrm{p}$ is not significant. $\mathrm{SD}=$ self-determination. $\mathrm{CM}=$ Confucian mindset.

\section{CONCLUSIONS}

\subsection{Theoretical implication}

Spiritual leadership is an emerging leadership construct worldwide that requires validation in diverse cultural settings (Benefiel et al., 2014) and diverse investigation on how and through what mechanisms spirituality is manifest in organizational outcomes, such as organizational citizenship behavior (Hill et al., 2013; Pawar, 2009). The results of this study suggest two main conclusions to theory.

First, this study was the first to explore the role self-determination plays in the relationship between spiritual leadership and OCBs, which found a surprisingly high path coefficient of .40 between selfdetermination and OCBO (as compared to a coefficient of .44 between meaning and OCBO). Moreover, mediation analysis confirmed that the indirect effects of self-determination $(\beta=.13)$ almost equaled the indirect effects of meaning $(\beta=.15)$ on OCBO. This suggests that in addition to a sense of meaning, the sense of autonomy and control over how to do their work that employees find from the influence of spiritual leadership is another mechanism to spur employees to adjust their work roles to improve the functioning of the organization. Hence, this research has shown that empowerment dimensions contribute differently to organizational outcomes (Spreitzer, 2008) and organizational leadership should embrace and emphasize diverse aspects of empowerment, including self-determination, as an effective tool in helping employees endorse OCBs. 
However, the influence of spiritual leadership on self-determination was significantly less than meaning, accounting for only $15 \%$ of the explained variance (versus $53 \%$ to meaning). A possible explanation may be that employees' sense of self-determination depends on leaders specifically and systematically increasing employees' sense of power over work processes, a form of developmental leadership and high-performance managerial practices that can generate a desire to more actively participate in discretionary citizenship behaviors (Ryan \& Deci, 2000; Spreitzer, 1995; Zhang \& Chen, 2013).

Second, this study began to explore the conditions through which spiritual leadership influences OCBs. The current study found that employees' Confucian mindset moderates the relationship between selfdetermination and OCBs. First, the results suggest that the level of employee OCBO, as influenced by the intervening influence of employees' sense of self-determination, may be explained in part by the degree to which employees endorse Confucian values, consistent with previous research on the moderating relationship of Confucian-based traditionality on work outcomes (Farh et al., 2007). More specifically, employees who more fully endorse Confucian values, such as empathy, conscientiousness, and respect for leaders, are more likely to take action to protect the organization and fight for its image.

Some of the moderation findings related to OCBI were contrary to hypothesized relationships. A possible explanation may be in the items comprising Confucian mindset and how these items correlate with perceptions to the individual or organization. As shown in Table 1, the correlation between selfdetermination and second-order dimension of Confucian mindset was only .18. Probing these correlations with first-order dimensions revealed that self-determination was correlated with Confucian work ethic $(\mathrm{r}=.22)$ but the correlation with relational harmony was low and only marginally significant $(\mathrm{r}=.11, p<.10)$. Given that relational harmony is closely tied to OCBI while Confucian work ethic is more closely tied to $\mathrm{OCBO}$, the probed correlation effects provide some support as to why Confucian values conditionally moderate the relationship of self-determination to OCBO but not OCBI.

\subsection{Practical implications}

The findings of this paper indicate that understanding OCB within a Confucian cultural context requires a focus on how employees comprehend and endorse Confucian cultural values that are impacting their sense of self-determination. As shown in this study, employees' sense of self-determination is impacted by the embedded cultural values of Confucianism, which remain deeply engrained in Koreans and their organizations. Indeed, the culture of Korean organizations is heavily influenced by Confucian attitudes and traditions that are perpetuated through in-house socialization, observational learning, and relational interactions (Bolino \& Turnley, 2003; Rowley \& Paik, 2009). Hence, as a starting point, the results of this study suggest focusing on the training and socialization processes pursued within organizations.

The findings of this study suggest a formal approach to training employees on the potential benefits of Confucian values can influence organizational outcomes. As described by Schuman (2015) through various examples, such an approach can yield unexpected, positive results. Schuman explains that the founder of a small company in China turned to the teachings of Confucianism in an attempt to boost efficiency and productivity. He began discussing Confucian ideals in morning meetings, which also included inviting experts to more formally teach staff members. He explains,

The Confucian thought went into their minds and changed their behavior. Before I introduced Confucianism, the employees would come in to work at 8:30 a.m. and leave at 5:30 p.m. exactly. They didn't want to spend one extra minute in the office. Now they voluntarily work more time. (Schuman, 2015, p. 168) 
The benefits of Confucianism also improved the cofounder. He claims,

I used to just care about how my employees could make money for me. Now I want to provide good jobs for my employees. I see them as my family and I want to take care of them. I focus not on moneymaking but improving myself and my employees on a spiritual level. (Schuman, 2015, p. 168)

These descriptive comments support the potentials benefits to both employees and the organization from conscious HRM character training on Confucian values and practices. As shown, such training can be relatively informal through emphasizing Confucian values and concepts in brief, team-based morning meetings, or more formal through inviting experts to expound on Confucian practices and the relationship to organizational behavior. Through such training and leader modeling, organizational cultures can become more spiritual, appealing to employees' inner desires for respect and purpose (Fry, 2003), which in turn can enhance employees' motivation to participate in OCBs.

\subsection{Limitations}

A limitation of this study was the use of a cross-sectional design, which limited an assessment of cause and effect. In this context, the current study cannot rule out alternative explanations as to how employees gain a sense of self-determination and why self-determined employees endorse the practice of OCBs. Another limitation of the study is the characteristics of the sample. The sample was purposively selected, based on prior investigation of the cultures of the sample organizations in order to more effectively understand how spiritual leadership exerts its effect on OCBs, and under what conditions Confucian values affect this relationship. However, whether the results of this study would generalize to other types of organizations or to cultural contexts outside of Korea is unknown. Thus, the findings of this paper should be examined in future research involving a broader sample of organizations with diverse demographics. Moreover, to generalize this study beyond a Korean context, cross-cultural analysis of the relationship between spiritual leadership and Confucian values should be investigated.

\section{ACKNOWLEDGEMENTS}

This work was supported by the Ministry of Education of the Republic of Korea and the National Research Foundation of Korea (NRF-2015S1A5A8016588).

\section{REFERENCES}

Anderson, J. C., \& Gerbing, D. W. (1988). Structural equation modeling in practice: A review and recommended two-step approach. Psychological Bulletin, 103(3), 411-423.

Bandura, A. (1986). Social foundations of thought and action: A social cognitive theory. Upper Saddle River, NJ: Prentice Hall.

Baron, R. M., \& Kenny, D. A. (1986). The moderator-mediator variable distinction in social psychological research: Conceptual, strategic, and statistical considerations. Journal of Personality and Social Psychology, 51(6), 1173-1182.

Bass, B. M., \& Avolio, B. J. (1994). Improving organizational effectiveness through transformational leadership. Thousand Oaks, CA: Sage. 
Becton, J. B., \& Field, H. S. (2009). Cultural differences in organizational citizenship behavior: A comparison between Chinese and American employees. The International Journal of Human Resource Management, 20(8), 1651-1669.

Bell, D. A., \& Hahm, C. (2003). Introduction: The contemporary relevance of Confucianism. In D. A. Bell \& C. Hahm (Eds.), Confucianism for the modern world (pp. 1-28). New York: Cambridge University Press.

Benefiel, M., Fry, L. W., \& Geigle, D. (2014). Spirituality and religion in the workplace: History, theory, and research. Psychology of Religion and Spirituality, 6(3), 175-187.

Bentler, P. M., \& Bonett, D. G. (1980). Significance tests and goodness of fit in the analysis of covariance structures. Psychological Bulletin, 88(3), 588-606.

Bolino, M. C., \& Turnley, W. H. (2003). Going the extra mile: Cultivating and managing employee citizenship behavior. The Academy of Management Executive, 17(3), 60-71.

Browne, M. W., \& Cudeck, R. (1993). Alternative ways of assessing model fit. In K. A. Bollen, \& J. S. Long (Eds.), Testing structural equation models (pp. 136-162). Newbury Park, CA: Sage.

Chen, C., \& Yang, C. (2012). The impact of spiritual leadership on organizational citizenship behavior: A multi-sample analysis. Journal of Business Ethics, 105(1), 107-114.

Conger, J. A., \& Kanungo, R. N. (1988). The empowerment process: Integrating theory and practice. Academy of Management Review, 13(3), 471-482.

Covey, S. R. (1991). Principle centered leadership. New York: Fireside.

Cropanzano, R., \& Mitchell, M. S. (2005). Social exchange theory: An interdisciplinary review. Journal of Management, 31(6), 874-900.

Daly, P. S., DuBose, P. B., Owyar-Hosseini, M. M., Baik, K., \& Stark, E. M. (2015). Antecedents of organizational citizenship behavior in a sample of Korean manufacturing employees. International Journal of Cross Cultural Management, 15(1), $27-50$.

Deci, E. L., \& Ryan, R. M. (1985). Intrinsic motivation and self-determination in human behaviour. New York: Plenum.

Deci, E. L., Connell, J. P., \& Ryan, R. M. (1989). Self-determination in a work organization. Journal of Applied Psychology, 74(4), 580-590.

Diener, E. (1984). Subjective well-being. Psychological Bulletin, 95(3), 542-575.

Edwards, J. R., \& Rothbard, N. P. (2000). Mechanisms linking work and family: Clarifying the relationship between work and family constructs. Academy of Management Review, 25(1), 178-199.

Farh, J., Hackett, R. D., \& Liang, J. (2007). Individual-level cultural values as moderators of perceived organizational support-employee outcome relationships in china: Comparing the effects of power distance and traditionality. Academy of Management Journal, 50(3), 715-729.

Farh, J., Zhong, C., \& Organ, D. W. (2004). Organizational citizenship behavior in the people's republic of China. Organization Science, 15(2), 241-253.

Fock, H., Chiang, F., Au, K. Y., \& Hui, M. K. (2011). The moderating effect of collectivistic orientation in psychological empowerment and job satisfaction relationship. International Journal of Hospitality Management, 30(2), 319-328.

Fornell, C., \& Larcker, D. F. (1981). Evaluating structural equation models with unobservable variables and measurement error. Journal of Marketing Research, 18(1), 39-50.

Fry, L. W. (2003). Toward a theory of spiritual leadership. The Leadership Quarterly, 14(6), 693-727.

Fry, L. W. (2008). Spiritual leadership: State-of-the-art and future directions for theory, research, and practice. In J. Biberman, \& L. Tischler (Eds.), Spirituality in business: Theory, practice and future directions (pp. 106-124). New York: Palgrave.

Fry, L. W., \& Nisiewicz, M. (2013). Maximizing the triple bottom line through spiritual leadership. Stanford: Stanford Business Books.

Gagné, M., \& Deci, E. L. (2005). Self-determination theory and work motivation. Journal of Organizational Behavior, 26(4), 331-362. 
Garavan, T. (1997). The learning organization: A review and evaluation. The Learning Organization, 4(1), 18-29.

Giacolone, R. A., \& Jurkiewicz, C. L. (2003). Toward a science of workplace spirituality. In R. A. Giacolone \& C. L. Jurkiewicz (Eds.), Handbook of workplace spirituality and organizational performance (pp. 3-28). New York: M.E. Sharpe.

Greenleaf, R. K. (1977). Servant leadership: A journey into the nature of legitimate power and greatness. New York: Paulist Press.

Han, Y., \& Altman, Y. (2010). Confucian moral roots of citizenship behaviour in China. Asia-Pacific Journal of Business Administration, 2(1), 35-52.

Hayes, A. F. (2013). Introduction to mediation, moderation, and conditional process analysis: $A$ regression-based approach. New York: Guilford Press.

Hayes, A. F., \& Matthes, J. (2009). Computational procedures for probing interactions in OLS and logistic regression: SPSS and SAS implementations. Behavior Research Methods, 41(3), 924-936.

Hemmert, M. (2012). Tiger management. New York: Routledge.

Hemmert, M. (2014). The business system of Korea. In H. Hasegawa, \& C. Noronha (Eds.), Asian business and management: Theory, practice and perspectives (pp. 219-238). New York: Palgrave MacMillan.

Hill, P. C., Jurkiewicz, C. L., Giacalone, R. A., \& Fry, L. W. (2013). From concept to science: Continuing steps in workplace spirituality research. In R. F. Paloutzian, \& C. L. Park (Eds.), Handbook of the psychology of religion and spirituality ( $2^{\text {nd }}$ ed., pp. 617-631). New York: Guilford Press.

Hofstede, G. (2001). Culture's consequences: Comparing values, behavior, institutions, and organizations across nations. Thousand Oaks, CA: Sage.

Hofstede, G., \& Hofstede, G. J. (2005). Cultures and organizations. New York: McGraw Hill.

House, R. J., \& Aditya, R. N. (1997). The social scientific study of leadership: Quo Vadis? Journal of Management, 23(3), 409-473.

House, R. J., Hanges, P. J., Javidan, M., Dorfman, P. W., \& Gupta, V. (Eds.). (2004). Culture, leadership, and organization: The GLOBE study of 62 societies. Thousand Oaks, CA: Sage.

Hunsaker, W. D. (2014). Relationship of Confucian values to spiritual leadership in a South Korean context. Asian Social Science, 10(12), 130-141.

Hunsaker, W. D. (2016). Spiritual leadership and organizational citizenship behavior: Relationship with Confucian values. Journal of Management, Spirituality \& Religion, 13(3), 206-225.

Jeon, K. S., Passmore, D. L., Lee, C., \& Hunsaker, W. (2013). Spiritual leadership: A validation study in a Korean context. Journal of Management, Spirituality \& Religion, 10(4), 342-357.

Katz, D. (1964). The motivational basis of organizational behavior. Systems Research and Behavioral Science, 9(2), 131-146.

Kazemipour, F., Mohamad Amin, S., \& Pourseidi, B. (2012). Relationship between workplace spirituality and organizational citizenship behavior among nurses through mediation of affective organizational commitment. Journal of Nursing Scholarship, 44(3), 302-310.

Kim, A. E., \& Park, G. (2003). Nationalism, Confucianism, work ethic and industrialization in south Korea. Journal of Contemporary Asia, 33(1), 37-49.

Kim, C. B., \& Shute, R. W. (1993). A Confucian theory of leadership. Provo, UT: Graham Maughan.

Kirkman, B. L., \& Shapiro, D. L. (2001). The impact of team members' cultural values on productivity, cooperation, and empowerment in self-managing work teams. Journal of Cross-Cultural Psychology, 32(5), 597-617.

Lawler, E. E. (1973). Motivation in work organizations. Monterey, CA: Brooks/Cole.

Lee, K., \& Allen, N. J. (2002). Organizational citizenship behavior and workplace deviance: The role of affect and cognitions. Journal of Applied Psychology, 87(1), 131-142. 
Marsh, H. W., \& Hocevar, D. (1985). Application of confirmatory factor analysis to the study of selfconcept: First-and higher order factor models and their invariance across groups. Psychological Bulletin, 97(3), 562-582.

Milliman, J., Czaplewski, A. J., \& Ferguson, J. (2003). Workplace spirituality and employee work attitudes: An exploratory empirical assessment. Journal of Organizational Change Management, 16(4), 426-447.

Organ, D. W. (1988). Organizational citizenship behavior: The good soldier syndrome. Lexington, MA: Lexington Books.

Organ, D. W. (1997). Organizational citizenship behavior: It's construct clean-up time. Human Performance, 10(2), 85-97.

Organ, D. W., Podsakoff, P. M., \& MacKenzie, S. B. (2006). Organizational citizenship behavior: Its nature, antecedent, and consequences. Thousand Oaks, CA: Sage.

Pawar, B. S. (2009). Some of the recent organizational behavior concepts as precursors to workplace spirituality. Journal of Business Ethics, 88(2), 245-261.

Pfeffer, J. (2010). Business and the spirit: Management practices that sustain values. In R. A. Giacolone, \& C. L. Jurkiewicz (Eds.), Handbook of workplace spirituality and organizational performance (pp. 27-43). New York: M.E. Sharpe.

Podsakoff, N. P., Whiting, S. W., Podsakoff, P. M., \& Blume, B. D. (2009). Individual-and organizational-level consequences of organizational citizenship behaviors: A metaanalysis. Journal of Applied Psychology, 94(1), 122-141.

Podsakoff, P. M., MacKenzie, S. B., Paine, J. B., \& Bachrach, D. G. (2000). Organizational citizenship behaviors: A critical review of the theoretical and empirical literature and suggestions for future research. Journal of Management, 26(3), 513-563.

Preacher, K. J., \& Hayes, A. F. (2004). SPSS and SAS procedures for estimating indirect effects in simple mediation models. Behavior Research Methods, 36(4), 717-731.

Preacher, K. J., Rucker, D. D., \& Hayes, A. F. (2007). Addressing moderated mediation hypotheses: Theory, methods, and prescriptions. Multivariate Behavioral Research, 42(1), 185-227.

Robert, C., Probst, T. M., Martocchio, J. J., Drasgow, F., \& Lawler, J. J. (2000). Empowerment and continuous improvement in the United States, Mexico, Poland, and India: Predicting fit on the basis of the dimensions of power distance and individualism. Journal of Applied Psychology, 85(5), 643-658.

Rowley, C., \& Paik, Y. (2009). Setting the scene for the changing face of South Korean management. In C. Rowley, \& Y. Paik (Eds.), The changing face of Korean management (pp. 1-28). New York: Routledge.

Ryan, R. M., \& Deci, E. L. (2000). Self-determination theory and the facilitation of intrinsic motivation, social development, and well-being. American Psychologist, 55(1), 68-78.

Ryan, R. M., \& Deci, E. L. (2017). Self-determination theory: Basic psychological needs in motivation, development, and wellness. New York: Guilford Publishing.

Ryu, S. Y. (2007). Item development for Korean Confucian values [Korean]. Korean Journal of Management, 15(4), 171-205.

Ryu, S. Y., \& Lee, K. (2010). A validation study of Kunja's leadership [Korean]. Korean Journal of Psychology, 29(1), 71-101.

Schein, E. H. (2004). Organizational culture and leadership. San Francisco, CA: Jossey-Bass.

Schuman, M. (2014). Confucius: And the world he created. New York: Basic Books.

Seibert, S. E., Wang, G., \& Courtright, S. H. (2011). Antecedents and consequences of psychological and team empowerment in organizations: A meta-analytic review. Journal of Applied Psychology, 96(5), 981-1003.

Senge, P. M. (1990). The fifth discipline: The art and practice of the learning organization. New York: Currency Doubleday. 
Spreitzer, G. M. (1995). Psychological empowerment in the workplace: Dimensions, measurement, and validation. Academy of Management Journal, 38(5), 1442-1465.

Spreitzer, G. M. (2008). Taking stock: A review of more than twenty years of research on empowerment at work. In J. Barling, \& C. L. Cooper (Eds.), Handbook of organizational behavior (pp. 54-72). Thousand Oaks, CA: Sage.

Tucker, L. R., \& Lewis, C. (1973). A reliability coefficient for maximum likelihood factor analysis. Psychometrika, 38(1), 1-10.

Wat, D., \& Shaffer, M. A. (2005). Equity and relationship quality influences on organizational citizenship behaviors: The mediating role of trust in the supervisor and empowerment. Personnel Review, 34(4), 406-422.

Wilensky, H. L. (1960). Work, careers and social integration. International Social Science Journal, 12(4), 543-560.

Williams, L. J., \& Anderson, S. E. (1991). Job satisfaction and organizational commitment as predictors of organizational citizenship and in-role behaviors. Journal of Management, 17(3), 601-617.

Woods, P. R., \& Lamond, D. A. (2011). What would Confucius do? - Confucian ethics and selfregulation in management. Journal of Business Ethics, 102(4), 669-683.

Zhang, Y., \& Chen, C. C. (2013). Developmental leadership and organizational citizenship behavior: Mediating effects of self-determination, supervisor identification, and organizational identification. The Leadership Quarterly, 24(4), 534-543.

Zhong, J. A., Lam, W., \& Chen, Z. (2011). Relationship between leader-member exchange and organizational citizenship behaviors: Examining the moderating role of empowerment. Asia Pacific Journal of Management, 28(3), 609-626. 